\title{
HIERARQUIA URBANA E CRIAÇÃO DE MUNICÍPIOS: ANÁLISE ESPACIAL DOS IMPACTOS DA CRIAÇÃO DE MUNICÍPIOS NOS POLOS REGIONAIS NOS PERÍODOS DEMOCRÁTICOS DE 1946-1964 E PÓS-1988
}

\author{
Tiago Cisalpino PINHEIRO ${ }^{1}$ \\ João Francisco $A B R E U^{2}$
}

\section{Resumo}

O processo de criação de municípios no Brasil está intimamente ligado aos ciclos políticos de centralização e descentralização do poder no século XX. Os períodos de regimes formalmente democráticos de 1946 e 1964 e pós-1988 com a redemocratização foram os períodos mais intensos da história brasileira de criação de municípios. Nesses períodos foram criados cerca de $70 \%$ dos municípios hoje existentes. Esse processo resulta em grandes distorções espaciais na transferência de repasses federais entre estados e regiões do Brasil favorecendo as regiões que concentraram a criação de novas unidades em ambos os períodos. Além disso, como o número de novas unidades municipais criadas tinham pequena população e ao mesmo tempo oferta restrita de comércio e serviços, já que desempenhariam as funções mais baixas da hierarquia urbana a criação massiva de novas unidades também traria impactos profundos sobre os polos urbanos de destaque nas regiões de concentração de novos municípios. A criação de um grande número de novos municípios na área de influência dos polos resultaria no aumento da renda da área de mercado do polo, que se traduziria em aumento na demanda de comércio e serviços dos polos que mais receberam novos municípios pequenos no seu entorno.

Palavras-chave: Geografia Urbana. Economia Regional. Finanças Públicas. Descentralização Fiscal. História Urbana. História Política.

\footnotetext{
1 Pós-doutorando em geografia - Tratamento da Informação Espacial PUC Minas - Avenida Itaú 505, Bairro Dom Cabral - Belo Horizonte/MG - CEP: 30535012. E-mail: tcisalpino@gmail.com

2 Professor do Programa de Pós-Graduação em Geografia - Tratamento da Informação Espacial PUC Minas - Avenida Itaú 505, Bairro Dom Cabral - Belo Horizonte/MG - CEP: 30535012. E-mail: jofaberu@pucminas.br
} 


\section{Abstract}

\section{Urban Hierarchy and the creation of municipalities: Spatial Analysis of the impacts of the creation of new municipalities on urban poles during the democratic periods of 1946-64 and after 1988}

The democratic periods of the XX century, the Populist Period (1946-1964) and recent democratization after 1988 were clear cycles of strong decentralization, and a common set of decentralization measures regarding political and fiscal aspects favored the occurrence of two intense cycle of creation of new municipalities associated to these democratic periods. Another common aspect is that on both periods 1946-64 and after 1988 , more than $80 \%$ of the municipalities created have a very small population associated with very low urban functions. During 1946 to 1964 more than 2.000 new municipalities were created and after 1988 more than 1.400 which represents $65 \%$ of total number of municipalities today, but also more $80 \%$ of the municipalities with less than 10 thousand people and $95 \%$ of the municipalities with less than 2000 . The spatial concentration of this phenomenon on particular regions makes this still more interesting because some states and particular regions on those states concentrated most of the new small municipalities, and also benefited some particular regional urban poles while the creation of small municipalities increases the federal transfer to some particular regions but also to some particular pole's hinterland favoring some instead of others regions and poles.

Key words: Urban Geography. Political Decentralization. Regional Science. Regional Economics.

\section{INTRODUÇÃO}

A criação de municípios no Brasil é um tema que traz questões ainda pouco exploradas pela análise espacial e a geografia. A concentração espacial da criação de municípios brasileiros em algumas regiões traz implicações econômicas e geográficas por conta de particularidades do fenômeno brasileiro de descentralização. Como os novos municípios têm sua economia altamente dependente dos repasses federais, a criação de um grande número de municípios em algumas regiões implica em aumento da renda disponível nessas regiões. Esse processo resultou numa redistribuição dos recursos públicos oriundos de transferências federais entre as regiões brasileiras. Estados e regiões que criaram um grande número de municípios nos períodos de democratização passaram a receber maior volume de repasses federais em comparação com regiões não criaram ou criaram poucos municípios.

Além da enorme quantidade de novos municípios criados, na escala dos milhares, a grande maioria tem pequeno porte populacional. Municípios de pequeno porte populacional possuem a característica intrínseca de apresentarem funções urbanas mais simples, hierarquicamente inferiores, que estão associadas a um pequeno porte e baixa diversidade da oferta de comércio e serviços. Aumentar a renda de municípios que não dispõem de funções urbanas hierarquicamente superiores implica que o aumento da demanda dessas funções seja realizado nas cidades polo, dotadas das funções urbanas mais complexas. Nesse contexto, os polos regionais das regiões mais beneficiadas pelo processo tenderiam a absorver esse fluxo de recursos resultante do processo de criação de municípios em suas áreas de influência. Baseado nas hipóteses geográficas descritas anteriormente foi avaliado o impacto dos ciclos de descentralização e criação de municípios nos polos regionais brasileiros. Vamos analisar os dois períodos democráticos do século $\mathrm{XX}$, o primeiro ciclo denominado pelos historiadores como República Populista de 1946 a 1964 e pós-1988. 


\section{REDES URBANAS}

Um dos fundamentos teóricos para entender o problema das emancipações no entorno de polos urbanos é o de redes urbanas. Para Corrêa (2006, p.26): "Uma rede urbana consiste num conjunto funcionalmente articulado de centros urbanos e suas hinterlândias, envolvendo uma complexa diferenciação entre cidades". Os estudos dedicados à hierarquia urbana tem como base a Teoria dos Lugares Centrais de Walter Christaller. Na visão de Hartshorn (1980), a Teoria dos Lugares Centrais apresenta um mecanismo conceitual para a compreensão das cidades como um centro de serviço. Seu papel de polo de uma região complementar ou hinterlândia, a cidade consiste no fornecedor de bens e serviços para seu entorno rural, formando um sistema interdependente da cidade e sua região de influência. O conceito de lugar central seria derivado da noção básica de interdependência entre uma cidade e seu entorno.

King (1984) destaca a existência de uma interdependência funcional entre uma cidade e a área rural no seu entorno. Para Christaller (1966), a principal característica de uma cidade é a de ser o centro de uma determinada região. Essa relação de interdependência funcional amplia-se na medida em que subimos de nível na hierarquia dos lugares centrais. Quanto maior a hierarquia do lugar central, maior a sua área de mercado dos bens e serviços encontrados nesse lugar central, e maior a capacidade do lugar central de atender as demandas do seu entorno, não somente da área rural, mas das cidades hierarquicamente inferiores. Essa dependência funcional ocorre entre os lugares centrais de hierarquia inferior aos lugares centrais de hierarquia superior.

Os conceitos das teorias da rede urbana, hinterlândia e teoria dos lugares centrais de Christaller fornecem subsídios importantes para a compreensão do impacto da criação de novos municípios nos polos regionais. Com a intensa criação novos municípios de pequeno porte aumenta muito a renda transferida para regiões especificas o que consequentemente tende a aumentar a demanda de comércio e serviços dos polos regionais que concentram os serviços de hierarquia superior. A criação de uma maioria de municípios muito pequenos sugere que grande parte dos municípios criados no Brasil atendeu critérios políticos e não demográficos. De modo que a sua criação não atenderia a um processo de crescimento populacional onde determinada localidade atingisse determinado porte e assim fosse emancipada, mas localidades estagnadas em termos de população e crescimento econômico foram emancipadas. Assim a criação gera um acréscimo de renda inesperado nessa região por conta quase que exclusiva do aumento das trasferências.

\section{DESCENTRALIZAÇÃo E CRIAÇÃo DE MUNICÍPIOS NO BRASIL}

A história política do Brasil é marcada por ciclos relativamente bem definidos de centralização e descentralização do poder. Os grandes ciclos de descentralização político e territorial relacionados aos períodos de base constitucional democrática que ocorreram na transição de ciclos autoritários, os períodos entre 1946 e 1964 e pós1988 merecem atenção porque neles foram criados cerca de 70\% dos municípios brasileiros hoje existentes.

O encerramento dos ciclos autoritários da Ditadura Vargas, com a Constituição de 1946 e da Ditadura Militar, com a Constituição de 1988, ocasionaram profundas alterações sobre o desenho político do território no nível local, municipal. Foram criados cerca de 1.400 novos municípios no pós-1988 e cerca de 2.000 entre 1946 e 
1964. A figura 1 mostra a relação entre os períodos democráticos e a intensidade de criação de municípios no país.

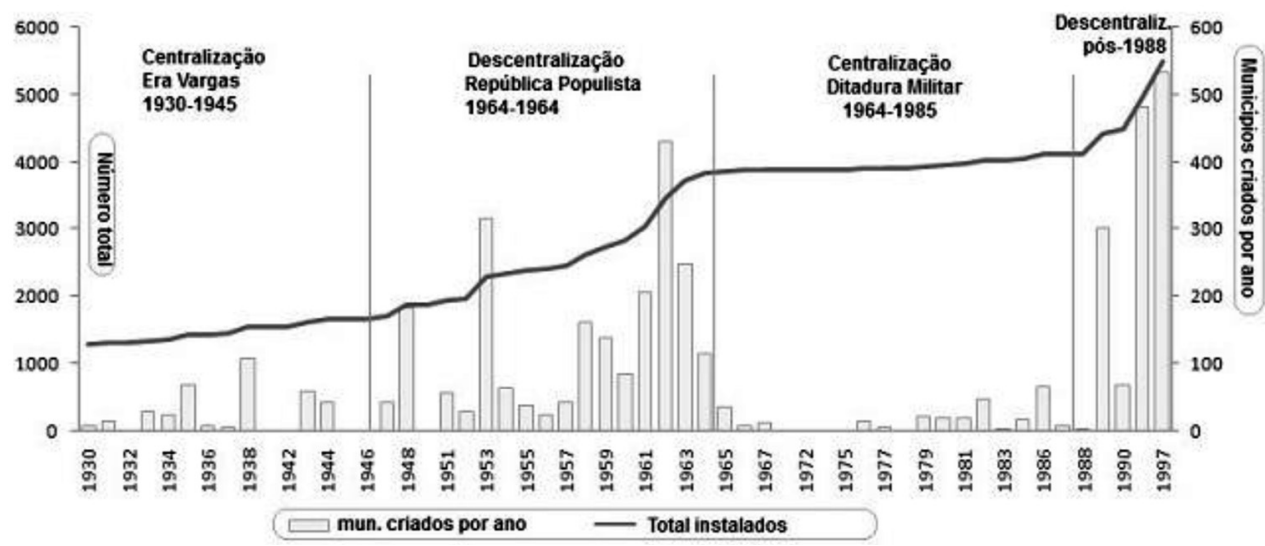

Figura 1 - Número de municípios criados por ano e número total de municípios do Brasil entre 1930 e 1997

Os municípios criados nesses períodos representam $80 \%$ dos municípios hoje com menos de 10.000 habitantes, $91 \%$ daqueles com menos de 5.000 e $95 \%$ dos municípios com menos de 2.000 habitantes. A tabela 1 apresenta a base para essas afirmações. Tabela 1 - Municípios criados nos períodos democráticos
por classe de população

\begin{tabular}{|c|c|c|c|c|c|c|c|}
\hline \multirow{2}{*}{$\begin{array}{l}\text { Classe de população } \\
\text { (Habitantes) }\end{array}$} & \multicolumn{2}{|c|}{ Pós-1988 } & \multicolumn{2}{|c|}{$1946-64$} & \multicolumn{2}{|c|}{$\begin{array}{c}\text { Sub-Total } \\
1946-64 \text { e pós-1988 }\end{array}$} & \multirow[t]{2}{*}{ Total } \\
\hline & $n$ & $\%$ & $\mathrm{n}$ & $\%$ & $\mathrm{~N}$ & $\%$ & \\
\hline até 2000 & 64 & 61,5 & 35 & 33,65 & 99 & 95,2 & 104 \\
\hline de 2 a 5 mil & 618 & 50,5 & 495 & 40,47 & 1.113 & 91,0 & 1.223 \\
\hline de 5 a $10 \mathrm{mil}$ & 396 & 30,2 & 641 & 48,93 & 1.037 & 79,2 & 1.310 \\
\hline de 10 a $20 \mathrm{mil}$ & 230 & 16,7 & 598 & 43,30 & 828 & 60,0 & 1.381 \\
\hline de 20 a $50 \mathrm{mil}$ & 61 & 6,3 & 225 & 23,34 & 286 & 29,7 & 964 \\
\hline de 50 a 100 mil & 11 & 3,7 & 39 & 12,96 & 50 & 16,6 & 301 \\
\hline de 100 a $200 \mathrm{mil}$ & 6 & 5,1 & 14 & 11,97 & 20 & 17,1 & 117 \\
\hline de 200 a $500 \mathrm{mil}$ & 1 & 1,3 & 15 & 19,74 & 16 & 21,1 & 76 \\
\hline de 500 mil a 1 milhão & 0 & 0,0 & 2 & 11,11 & 2 & 11,1 & 18 \\
\hline mais de 1 milhão & 0 & 0,0 & 1 & 7,69 & 1 & 7,7 & 13 \\
\hline Total & 1.387 & 25,2 & 2065 & 37,50 & 3452 & 62,7 & 5507 \\
\hline
\end{tabular}

Fonte: Elaboração própria a partir de dados da Secretaria do Tesouro Nacional e IBGE.

Um dos possíveis motivos do grande número de novos municípios criados nesse período deve-se as mudanças no sistema de distribuição dos recursos federais entre os entes federados. A constituição de 1946 definiu uma distribuição igualitária dos recursos, todos os municípios, independente do seu tamanho da sua população ou localização geográfica receberia a mesma cota de repasse federal. Assim, quanto menor a população residente no município, maior o repasse por habitante. 
Como os impostos federais eram distribuídos de forma igual entre os municípios é possível avaliar a distribuição de repasses federais para cada município ao longo desse período. A tabela 2 mostra a distribuição da arrecadação de Imposto de Renda federal entre os municípios classificados de acordo com a classe de população. Pode se observar claramente como os critérios de distribuição previstos na constituição de 1946 premiavam os municípios de menor população com maiores repasses por habitante.

Tabela 2 - População Residente, Fundo de Participação dos Municípios e FPM por habitante por classes de população 1970

\begin{tabular}{|c|c|c|c|c|c|c|}
\hline \multirow{2}{*}{ Classe de População } & \multirow{2}{*}{ Número } & \multicolumn{2}{|c|}{ População Residente 1970} & \multicolumn{2}{|c|}{ Repasse Federal 1970} & \multirow{2}{*}{$\begin{array}{c}\text { Cota por } \\
\text { habitante } \\
\%\end{array}$} \\
\hline & & $n$ & $\%$ & Crz\$ (milhões) & $\%$ & \\
\hline 01 -até $2 \mathrm{mil}$ & 57 & 92.392 & 0,10 & 1,56 & 1,5 & 16,90 \\
\hline $02-2$ a $5 \mathrm{mil}$ & 617 & 2.267 .575 & 2,43 & 16,27 & 15,5 & 7,17 \\
\hline $03-5$ a $10 \mathrm{mil}$ & 1079 & 7.943 .861 & 8,53 & 28,24 & 26,9 & 3,55 \\
\hline $04-10$ a $20 \mathrm{mil}$ & 1137 & 16.116 .112 & 17,30 & 30,29 & 28,9 & 1,88 \\
\hline $05-20$ a $50 \mathrm{mil}$ & 814 & 24.506 .112 & 26,31 & 21,86 & 20,8 & 0,89 \\
\hline $06-50$ a $100 \mathrm{mil}$ & 156 & 10.381 .988 & 11,15 & 4,25 & 4,0 & 0,41 \\
\hline $07-100$ a $200 \mathrm{mil}$ & 57 & 7.407 .353 & 7,95 & 1,53 & 1,5 & 0,21 \\
\hline $08-200$ a $500 \mathrm{mil}$ & 23 & 6.685 .277 & 7,18 & 0,63 & 0,6 & 0,09 \\
\hline 09-500 a 1 milhão & 6 & 4.250 .557 & 4,56 & 0,16 & 0,2 & 0,04 \\
\hline 10-mais de 1 milhão & 5 & 13.479 .456 & 14,47 & 0,11 & 0,1 & 0,01 \\
\hline Total Geral & 3951 & 93.130 .683 & 100,00 & 104,93 & 100,0 & 1,13 \\
\hline
\end{tabular}

Fonte: Elaboração própria a partir de dados da Secretaria do Tesouro Nacional e IBGE.

No período pós 1988 a distribuição do Fundo de Participação dos Municípios, principal repasse federal para os municípios, a distribuição passou a ser feita tendo como principal critério cotas populacionais, porém, essas cotas continuariam a privilegiar as menores unidades municipais em termos de população com os maiores repasses por habitante. Uma situação dessas, combinada com a autonomia dos estados para a criação de novos municípios, incentivou a criação de unidades de pequeno porte populacional (GOMES E MAC DOWEL, 2000, TOMIO, 2000, 2005).

A tabela 3 ilustra as distorções da distribuição do FPM em relação ao tamanho do município.

\section{Tabela 3 - População Residente, Fundo de Participação dos Municípios e FPM por habitante por classes de população 2000}

\begin{tabular}{|c|c|c|c|c|c|c|}
\hline \multirow{2}{*}{ Classe de População } & \multirow{2}{*}{ Número } & \multicolumn{2}{|c|}{ População Residente 2000} & \multicolumn{2}{|c|}{ FPM 2000} & \multirow{2}{*}{$\begin{array}{c}\text { FPM por } \\
\text { habitante }\end{array}$} \\
\hline & & $\mathrm{n}$ & $\%$ & $\mathrm{R} \$$ (milhões) & $\%$ & \\
\hline 01-até 2 mil & 104 & 170.392 & 0,10 & $\mathrm{R} \$ 123$ & 0,87 & 724,70 \\
\hline $02-2$ a $5 \mathrm{mil}$ & 1223 & 4.306 .768 & 2,54 & $R \$ 1.525$ & 10,80 & 354,23 \\
\hline $03-5$ a $10 \mathrm{mil}$ & 1310 & 9.356 .732 & 5,51 & $\mathrm{R} \$ 1.680$ & 11,90 & 179,64 \\
\hline $04-10$ a $20 \mathrm{mil}$ & 1381 & 19.603 .512 & 11,55 & $R \$ 2.713$ & 19,21 & 138,42 \\
\hline $05-20$ a $50 \mathrm{mil}$ & 964 & 28.832 .600 & 16,98 & $R \$ 3.166$ & 22,41 & 109,81 \\
\hline $06-50$ a $100 \mathrm{mil}$ & 301 & 20.928 .128 & 12,33 & $\mathrm{R} \$ 1.531$ & 10,84 & 73,16 \\
\hline $07-100$ a $200 \mathrm{mil}$ & 117 & 16.406 .325 & 9,66 & $\mathrm{R} \$ 1.085$ & 7,68 & 66,16 \\
\hline $08-200$ a $500 \mathrm{mil}$ & 76 & 23.221 .680 & 13,68 & $\mathrm{R} \$ 1.102$ & 7,80 & 47,47 \\
\hline 09-500 a 1 milhão & 18 & 12.583 .713 & 7,41 & $\mathrm{R} \$ 461$ & 3,27 & 36,70 \\
\hline 10-mais de 1 milhão & 13 & $34.389 .320,00$ & 20,25 & $\mathrm{R} \$ 736$ & 5,21 & 21,40 \\
\hline Total Geral & 5507 & $169.799 .170,00$ & 100,00 & $\mathrm{R} \$ 14.126$ & 100,00 & 83,19 \\
\hline
\end{tabular}

Fonte: Elaboração própria a partir de dados da Secretaria do Tesouro Nacional e IBGE. 
Os municípios emancipados apresentam duas características marcantes: uma maior disponibilidade de repasses federais por habitante, combinada a uma estrutura bastante reduzida de atividades urbanas nas sedes municipais. Se essa análise for combinada com as teorias de hierarquização urbana e dos polos regionais, poder-seia esperar que se a área de influência de um determinado polo regional recebesse um grande número de emancipações, haveria um aumento de renda regional via aumento de repasses, e seria esperado ainda um aumento na movimentação econômica dos setores de comércio e serviços dos polos regionais.

\section{MATERIAIS E MÉTODOS}

As bases de dados utilizadas foram obtidas nos Censos Demográficos de 1940, 1950, 1960, 1970, 1991, 2000 e 2010 do IBGE, além de bases do PIB setorial do comércio e dos serviços disponíveis para os anos de 1939, 1949, 1959, 1970 e 1975. Utilizamos para análise dos dados técnicas de estatística multivariada que costumam ser utilizadas para sistematizar e classificar os dados, a análise de componentes principais e a análise de Cluster (agrupamentos). (GRIFFITH e AMRHEIN, 1997) (HAIR, 2008). A técnica permite reduzir uma grande matriz de dados em poucos componentes, que sintetizam a variabilidade da matriz multivariada original. A ideia é reter a natureza e as características das variáveis anteriores em um pequeno número de variáveis que podem ser utilizadas para múltiplos fins, inclusive análises multivariadas posteriores (HAIR et al., 2005).

A hierarquização foi construída a partir de uma matriz de dados com variáveis representativas do porte urbano década a década, a partir de 1940, ano censitário prévio ao primeiro ciclo de descentralização. Os dados abrangem os períodos de 1940, 1950, 1960, 1970, 1980, 1991, 2000 e 2010.

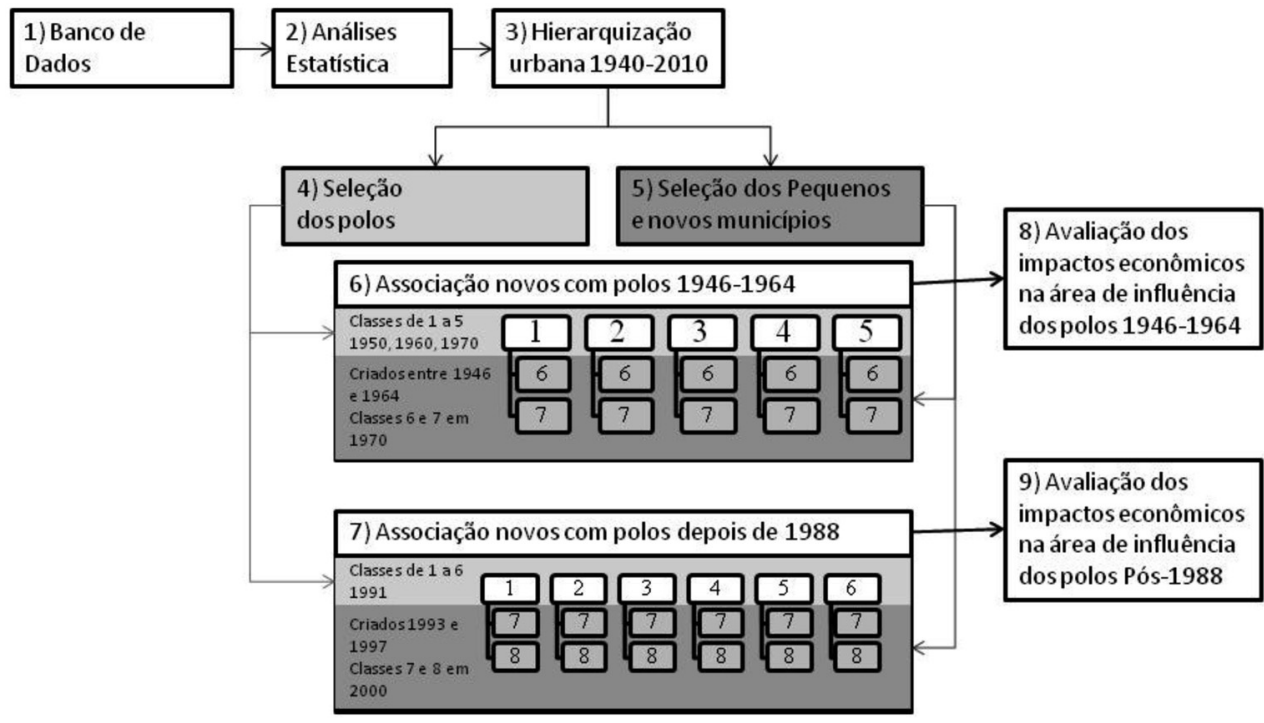

Figura 2 - Esquema ilustrativo do desenvolvimento da metodologia de hierarquização urbana e análise da criação de município 
A tabela 4 mostra a variância captada pelo componente 1 nas 8 análises realizadas para cada década mostra que o componente 1 da análise sintetiza mais de $95 \%$ da variabilidade dos dados em todos os casos analisados. Sendo assim podemos utilizar uma única variável, sintetizada pelo componente 1 em substituição ao conjunto de variáveis empregados na análise.

\section{Tabela 4 - Resultados da análise de componentes principais 1940-2000}

\begin{tabular}{c|c|c}
\hline Componente & Autovalor & \% Variância Total explicada \\
\hline $1-1940$ & 8.6230 & 95.81 \\
$1-1950$ & 7.7604 & 97.00 \\
$1-1960$ & 7.8340 & 97.92 \\
$1-1970$ & 8.7921 & 97.69 \\
$1-1980$ & 12,6450 & 97.27 \\
$1-1991$ & 6,7344 & 96.19 \\
$1-2000$ & 12,5478 & 96,52 \\
$1-2010$ & 16,6055 & 97.67 \\
\hline
\end{tabular}

Fonte: Elaboração do autor a partir de dados disponíveis no IPEADATA.

Um dos resultados da análise de componentes é denominado score, que consiste na combinação linear das variáveis e no posicionamento de cada um dos municípios em relação à componente síntese. Esse resultado serve como um índice representativo do conjunto de variáveis utilizadas, pois seu cálculo é obtido através de uma combinação linear das variáveis utilizadas na análise. No caso da análise que realizamos o score do componente 1 representa um índice de oferta de serviços nos municípios brasileiros, que permite ajudar na representação hierárquica da rede urbana brasileira. Para cada década será calculado o índice municipal de oferta de serviços e classificadas as sedes urbanas em sete agrupamentos relacionados à posição do polo na hierarquia urbana. A partir desses resultados, novamente os grupos serão mapeados para facilitar a identificação visual dos polos regionais.

\section{ANÁLISE ESPACIAL DO IMPACTO DA CRIAÇÃO DE MUNICÍPIOS NOS POLOS REGIONAIS}

Com o resultado da análise temos para todas as décadas entre 1940 e 2010 todos os municípios brasileiros existentes em cada censo classificados de acordo com a hierarquia urbana e com um índice particular de oferta de serviços, com isso podemos mostrar quais polos regionais seriam os maiores beneficiários do processo de criação de municípios em sua região de influência, como também, quais são os níveis hierárquicos dos novos municípios criados.

O primeiro grande ciclo de descentralização e criação de municípios ocorreria na experiência democrática do país entre 1946 e 1964. Os municípios criados entre 1946 e 1949 apareceriam discriminados nas estatísticas no censo de 1950, os municí- 
pios criados entre 1950 e 1959 apareceriam no Censo de 1960 e os municípios criados entre 1960 e 1964 apareceriam nas estatísticas do Censo de 1970. Por esse motivo, precisamos também saber quais os polos regionais que sofreriam influência do processo de criação de municípios ao longo de todo o processo de descentralização. Assim consideramos na análise do impacto da criação de municípios os polos regionais que se mantiveram no topo da hierarquia urbana ao longo dos Censos de 1950, 1960 e 1970. As tabelas 5, 6 e 7 mostram a média de algumas das variáveis utilizadas para hierarquização urbana dos municípios brasileiros. Vale notar como os agrupamentos conseguem são estáveis ao longo do período.

\section{Tabela 5 - Média das variáveis para cada um dos agrupamentos 1950}

\begin{tabular}{c|c|c|c|c|c|c|c}
\hline ano & $\mathrm{C}$ & $\mathrm{n}$ & $\begin{array}{c}\text { População } \\
\text { Total }\end{array}$ & $\begin{array}{c}\text { População } \\
\text { Urbana }\end{array}$ & $\begin{array}{c}\text { Índice de } \\
\text { Serviços } \\
1950\end{array}$ & $\begin{array}{c}\text { PIB Serviços } \\
1949\end{array}$ & $\begin{array}{c}\text { PIB Comércio } \\
1949\end{array}$ \\
\hline & 1 & 2 & $2,287,774$ & $2,177,603$ & 88.09 & $8,062,215$ & $2,322,722$ \\
& 2 & 5 & 378,471 & 363,411 & 12.63 & 919,414 & 512,049 \\
1950 & 3 & 4 & 223,001 & 197,824 & 5.58 & 378,159 & 142,570 \\
& 4 & 20 & 126,305 & 82,226 & 2.51 & 158,367 & 51,285 \\
& 5 & 107 & 70,917 & 28,992 & 1.13 & 54,049 & 13,160 \\
& 6 & 561 & 34,041 & 7,813 & 0.52 & 11,151 & 2,496 \\
1 & 1.191 & 12,905 & 2,827 & 0.33 & 3,680 & 707 \\
\hline & 1 & 2 & $3,261,813$ & $3,566,257$ & 94.745 & $4,233,990.75$ & $14,893,551$ \\
& 2 & 5 & 595,877 & 610,645 & 14.734 & $948,103.51$ & $2,059,839$ \\
& 3 & 3 & 400,901 & 426,099 & 7.737 & $398,037.53$ & $747,272.58$ \\
& 4 & 21 & 155,511 & 195,565 & 3.042 & $113,965.39$ & $310,810.23$ \\
& 5 & 100 & 52,675 & 87,953 & 1.284 & $36,102.85$ & $103,624.42$ \\
& 6 & 590 & 11,811 & 37,230 & 0.533 & $6,077.28$ & $19,942.01$ \\
& 7 & 2044 & 2,756 & 11,883 & 0.327 & $1,039.44$ & $3,595.99$ \\
\hline & 1 & 2 & $5,088,265$ & $5,062,118$ & 87.10 & $8,463,439$ & $29,152,326$ \\
& 2 & 4 & $1,047,118$ & $1,037,262$ & 14.31 & $1,482,493$ & $4,028,825$ \\
& 3 & 6 & 618,440 & 599,816 & 7.88 & 587,588 & $2,096,341$ \\
& 4 & 19 & 289,812 & 266,849 & 3.80 & 367,281 & 894,134 \\
& 5 & 69 & 127,788 & 107,656 & 1.64 & 97,135 & 273,863 \\
& 6 & 398 & 48,004 & 25,296 & 0.59 & 16,510 & 52,079 \\
& 7 & 3453 & 12,055 & 3,376 & 0.27 & 1,212 & 5,597 \\
\hline
\end{tabular}

Fonte: Elaboração própria a partir de dados do IBGE disponíveis no IPEADATA.

O mapa 1 mostra os polos regionais que se encontraram no topo da hierarquia urbana brasileira (Clusters 1 a 5) entre 1950 e 1970.

A distância euclidiana é a variável escolhida para associação entre os municípios criados e os polos. Assim, a cidade polo mais próximo dos municípios criados foi escolhida como o polo de influencia do novo município. Esse método tem problemas porque muitas vezes a distância euclidiana não é o principal fator de influência da definição de qual é o polo de influência, a geografia física e a rede de transportes influenciam fortemente essa relação. Porém entendemos que na escala da abordagem o método escolhido atende satisfatoriamente a resolução do problema. Assim definimos a área de influência de cada um dos polos regionais através de um algoritmo que identifica os polos mais próximos dos novos municípios criados. 


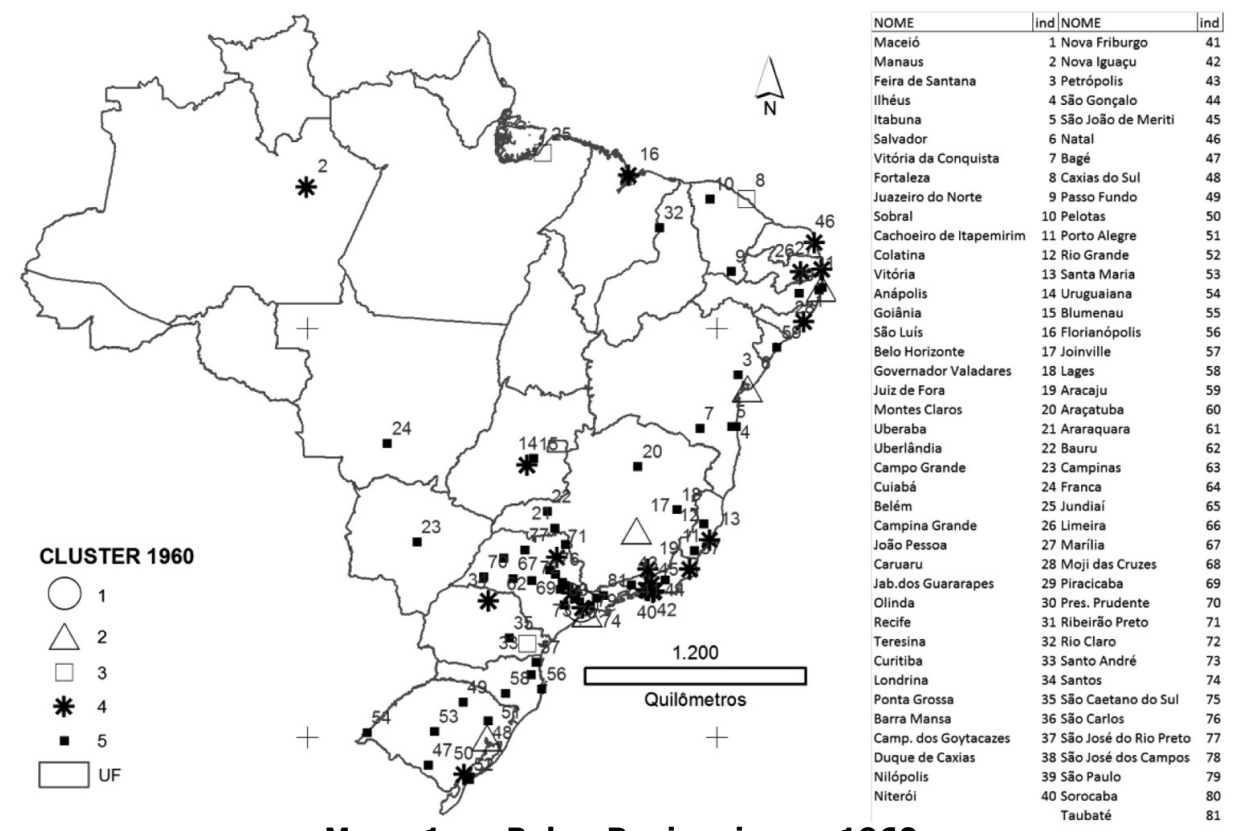

Mapa 1 - Polos Regionais em 1960

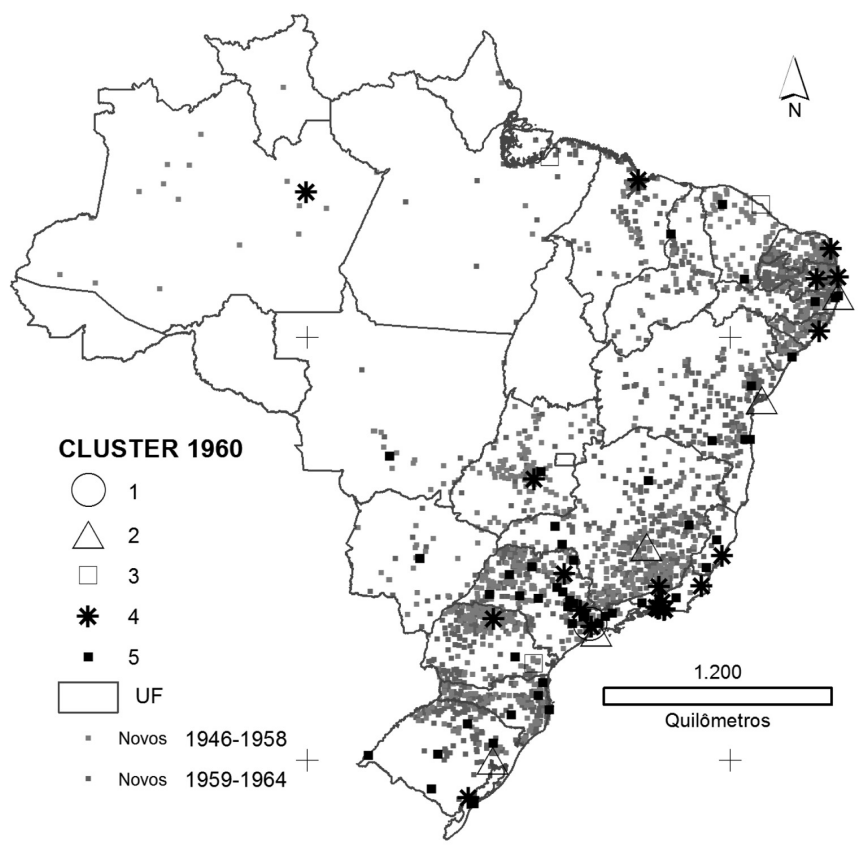

Mapa 2 - Polos Regionais 1960 e Novos municípios criados entre 1946-1964 
A tabela 6 mostra o número de novos municípios criados na área de influências polos urbanos que receberam o maior número de novos municípios em sua área de influência. Como pode ser notado no mapa 2 o fenômeno é distribuído espacialmente de forma concentrada em poucas regiões do país: as áreas de influência com os $20 \%$ maiores números de municípios responderam por mais de $50 \%$ do total de novas unidades e os $40 \%$ maiores totalizaram quase $75 \%$ das ocorrências. Essa situação sugere a possibilidade de que os polos e regiões que receberam o maior número de novas unidades no seu entorno podem ter se beneficiado economicamente desse processo.

As áreas de influência com os maiores números de novas unidades receberão os maiores repasses relativos de repasses federais, com devido reflexo na dinâmica das atividades econômica dessas regiões. Em alguns polos, a criação de municípios na sua área de influência foi tão intensa e o acréscimo relativo tão elevado que a maior parte das receitas repassadas aos municípios na área de influência foi resultado dos processos de criação de municípios. Em Passo Fundo e Londrina, por exemplo, as novas unidades representaram cerca de $90 \%$ dos recursos repassados em 1964, mas em todos os casos os índices dos principais polos, os índices de acréscimo de repasse, foram superiores a $50 \%$ do total repassado aos municípios das áreas de influência dos polos em 1964.

Tabela 6 - Número de novos municípios criados na área de influência dos polos regionais que mais receberam novas unidades entre 1946 e 1964

\begin{tabular}{|c|c|c|c|c|c|c|c|c|}
\hline Polos urbanos & 1946 & 1950 & 1960 & 1964 & $\begin{array}{c}n \text { de } \\
\text { municí- } \\
\text { pios } \\
\text { criados }\end{array}$ & rank $\mathrm{n}$ & $\%$ total & Quintil \\
\hline Londrina-PR & 12 & 31 & 128 & 150 & 138 & 1 & 6.32 & \\
\hline Passo Fundo-RS & 16 & 18 & 84 & 148 & 132 & 2 & 12.37 & \\
\hline Juazeiro do Norte-CE & 79 & 79 & 128 & 198 & 119 & 3 & 17.83 & \\
\hline Belo Horizonte-MG & 75 & 94 & 117 & 175 & 100 & 4 & 22.41 & \\
\hline Campina Grande-PB & 35 & 38 & 75 & 123 & 88 & 5 & 26.44 & \\
\hline Teresina-PI & 65 & 67 & 102 & 147 & 82 & 6 & 30.20 & \\
\hline Feira de Santana-BA & 55 & 55 & 73 & 121 & 66 & 7 & 33.23 & \\
\hline Presid. Prudente-SP & 13 & 25 & 62 & 78 & 65 & 8 & 36.21 & 20 \\
\hline Gov. Valadares-MG & 29 & 40 & 53 & 93 & 64 & 9 & 39.14 & maiores \\
\hline Vit. da Conquista-BA & 44 & 47 & 58 & 108 & 64 & 10 & 42.07 & \\
\hline Goiânia-GO & 22 & 34 & 70 & 81 & 59 & 11 & 44.78 & \\
\hline Juiz de Fora-MG & 34 & 39 & 62 & 93 & 59 & 12 & 47.48 & \\
\hline Natal-RN & 23 & 27 & 47 & 81 & 58 & 13 & 50.14 & \\
\hline Aracaju-SE & 59 & 61 & 93 & 114 & 55 & 14 & 52.66 & \\
\hline Araçatuba-SP & 23 & 31 & 65 & 77 & 54 & 15 & 55.13 & \\
\hline Caruaru-PE & 38 & 42 & 65 & 91 & 53 & 16 & 57.56 & \\
\hline Anápolis-GO & 19 & 25 & 55 & 70 & 51 & 17 & 59.90 & \\
\hline Montes Claros-MG & 25 & 29 & 38 & 76 & 51 & 18 & 62.24 & \\
\hline Maceió-AL & 25 & 27 & 49 & 65 & 40 & 19 & 64.07 & \\
\hline S. Jé do Rio Preto-SP & 33 & 41 & 61 & 71 & 38 & 20 & 65.81 & \\
\hline Itabuna-BA & 7 & 8 & 22 & 43 & 36 & 21 & 67.46 & \\
\hline Lages-SC & 11 & 14 & 27 & 47 & 36 & 22 & 69.11 & \\
\hline São Luís-MA & 33 & 39 & 51 & 65 & 32 & 23 & 70.58 & \\
\hline Blumenau-SC & 12 & 13 & 22 & 42 & 30 & 24 & 71.95 & $20-40$ \\
\hline Belém-PA & 53 & 55 & 58 & 81 & 28 & 25 & 73.24 & maiores \\
\hline Taubaté-SP & 48 & 54 & 61 & 76 & 28 & 26 & 74.52 & \\
\hline Campo Grande-MS & 13 & 17 & 28 & 40 & 27 & 27 & 75.76 & \\
\hline Franca-SP & 43 & 54 & 61 & 70 & 27 & 28 & 76.99 & \\
\hline Uberlândia-MG & 21 & 28 & 38 & 48 & 27 & 29 & 78.23 & \\
\hline Cachoeiro de Itapemirim-ES & 26 & 29 & 36 & 52 & 26 & 30 & 79.42 & \\
\hline Florianópolis-SC & 12 & 12 & 18 & 38 & 26 & 31 & 80.61 & \\
\hline Sobral-CE & 32 & 33 & 54 & 55 & 23 & 32 & 81.67 & \\
\hline Total & 1648 & 1874 & 2829 & 3830 & 2182 & 82 & 100 & Nsa \\
\hline
\end{tabular}

Fonte: Elaboração própria a partir de dados do IBGE disponíveis no IPEADATA. 
A tabela 7 mostra que as áreas de influência dos polos que receberam o maior número de novas unidades incrementaram sua renda regional a partir do aumento de transferências federais, em detrimento de outras áreas de influência, de maneira que possivelmente os impactos financeiros possam ter diferenciado a dinâmica econômica das cidades onde que receberam o maior número de emancipações municipais. 0 aumento das transferências federais em proporção maior para as áreas de influência com o maior número de municípios se traduziria também em aumento da transferência por habitante, da região, tendo em vista que, a cada novo ciclo de descentralização o tamanho médio do município se reduziria.

Tabela 7 - Repasse para as áreas de influência por área de influência (AI) dos polos classificadas por quintis de criação de novos municípios

\begin{tabular}{c|c|c|c|c|c|c}
\hline \multirow{2}{*}{$\begin{array}{c}\text { Quintis } \\
\text { das AIs } \\
\text { por } n \text { de } \\
\text { novos }\end{array}$} & \multicolumn{2}{|c|}{ Repasse 1950 } & \multicolumn{2}{c|}{ Repasse 1960} & \multicolumn{2}{c}{ Repasse 1964} \\
\cline { 2 - 7 } & CRZ (1966) & $\%$ & CRZ (1966) & $\%$ & CRZ (1966) & $\%$ \\
\hline 1 & $\mathrm{R} \$ 15,418,754$ & 33.75 & $\mathrm{R} \$ 34,348,694$ & 39.62 & $\mathrm{R} \$ 42,672,903$ & 42.98 \\
2 & $\mathrm{R} \$ 10,469,524$ & 22.92 & $\mathrm{R} \$ 20,080,775$ & 23.16 & $\mathrm{R} \$ 23,828,900$ & 24.00 \\
3 & $\mathrm{R} \$ 9,871,266$ & 21.61 & $\mathrm{R} \$ 16,711,961$ & 19.28 & $\mathrm{R} \$ 17,173,242$ & 17.30 \\
4 & $\mathrm{R} \$ 7,097,522$ & 15.54 & $\mathrm{R} \$ 10,998,187$ & 12.69 & $\mathrm{R} \$ 11,065,374$ & 11.14 \\
5 & $\mathrm{R} \$ 2,828,131$ & 6.19 & $\mathrm{R} \$ 4,557,807$ & 5.26 & $\mathrm{R} \$ 4,546,664$ & 4.58 \\
Total & $\mathrm{R} \$ 45,685,198$ & 100 & $\mathrm{R} \$ 86,697,424$ & 100 & $\mathrm{R} \$ 99,287,083$ & 100 \\
\hline
\end{tabular}

Fonte: Elaboração do autor a partir de bases de dados do IBGE.

Como suas regiões de influência dos polos estariam recebendo acréscimos crescentes na sua renda, por conta da expansão das transferências governamentais, seria de se esperar que os polos regionais que intermediariam esse processo sofressem forte acréscimo na demanda de bens e serviços ao cumprirem o papel de intermediação das atividades produtivas em ambas as regiões. Para ilustrar e avaliar esse hipótese os polos regionais foram classificados de acordo com o número de novos municípios criados em sua área de influência e nota-se que em ambos os casos a dinâmica tanto do setor de comércio quanto o de serviços dos que mais receberam novas unidade tiveram aumento cima dos polos que não foram beneficiados pelo processo.
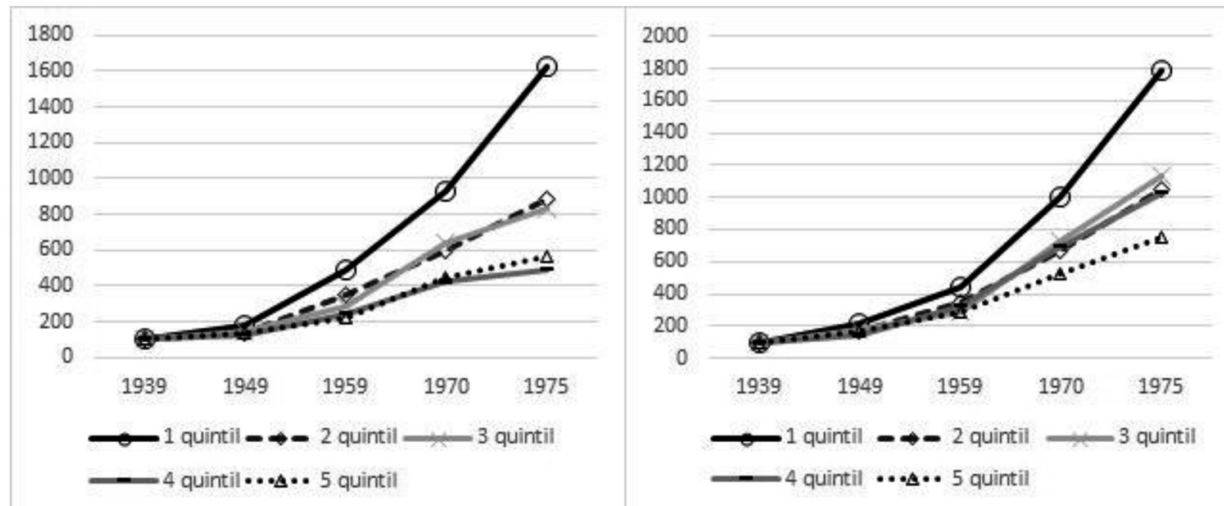

Figura 3 Índice de crescimento do PIB setor de comércio e serviços dos polos regionais 1960 classificados de acordo com o número de municípios criados em sua área de influência 
Os resultados mostram que quanto maior a posição do polo regional em relação ao número de novos municípios criados, maior o crescimento relativo do PIB do setor de comércio e do setor de serviços desses polos, entre 1940 e 1975.

Os resultados são favoráveis, mas merecem ser avaliados com cautela, pois não provam a existência de causalidade nem medem precisamente o impacto econômico dos novos municípios na renda regional, porém, apresentam fortes indícios de que esse processo de descentralização apresenta intenso potencial de dinamização das atividades de comércio e serviços dos polos regionais que receberam o maior número de novas unidades.

O gráfico 3 mostra que o PIB comércio dos polos regionais por quintil de novos municípios criados, transformados em números índices para facilitar a comparação entre eles, indica que os polos regionais que receberam o maior número de novos municípios apresentaram uma dinâmica de crescimento superior ao das demais unidades com menor número de novas unidades. Outro fato marcante consiste no período em que as diferenças se acentuam, entre 1959 e 1970, que como foi mostrado, concentrou a maior intensidade de criação de novas unidades municipais de nossa história republicana.

\section{Análise do Segundo Ciclo Democrático Pós-1988}

O segundo ciclo de descentralização pós-1988, teria uma semelhança muito grande com o período anterior que se traduziriam inclusive nos aspectos regionais da análise, de beneficiamento de regiões específicas e polos regionais, específicos.

As décadas de referência para a hierarquização prévia às emancipações de destaque do pós-1988, é o período de 1991 e 2000, ano em que estão disponíveis os resultados censitários. A seguir pode ser observado no mapa 3 os resultados para os principais indicadores de hierarquia urbana da análise de agrupamentos de 1991

Também foi realizada a hierarquização da rede urbana brasileira de 1991 até 2010. Com a classificação de 2000 que identificaremos os menores municípios criados no período.

\section{Tabela 8 - Média do Repasse federal por habitante para as áreas de influência por área de influência (AI) dos polos classificados por quintis de criação de novos municípios (Crz\$1966)}

\begin{tabular}{c|c|c|c|c}
\hline Row Labels & $\begin{array}{c}\text { Média da Repasse federal } \\
\text { Per capita 1950 }\end{array}$ & $\begin{array}{c}\text { Média da Repasse federal } \\
\text { Per capita 1960 }\end{array}$ & $\begin{array}{c}\text { Média da Repasse federal } \\
\text { Per capita 1964 }\end{array}$ & Variação \% \\
\hline 1 & $\mathrm{R} \$ 1,221.94$ & $\mathrm{R} \$ 2,046.89$ & $\mathrm{R} \$ 2,488.88$ & 104 \\
2 & $\mathrm{R} \$ 1,300.28$ & $\mathrm{R} \$ 1,938.58$ & $\mathrm{R} \$ 2,403.70$ & 85 \\
3 & $\mathrm{R} \$ 1,451.62$ & $\mathrm{R} \$ 2,017.25$ & $\mathrm{R} \$ 2,203.80$ & 52 \\
4 & $\mathrm{R} \$ 1,682.65$ & $\mathrm{R} \$ 2,264.93$ & $\mathrm{R} \$ 2,333.66$ & 39 \\
5 & $\mathrm{R} \$ 1,619.66$ & $\mathrm{R} \$ 2,085.16$ & $\mathrm{R} \$ 2,066.48$ & 28 \\
Total & $\mathrm{R} \$ 1,455.23$ & $\mathrm{R} \$ 2,070.56$ & $\mathrm{R} \$ 2,299.31$ & 58 \\
\hline
\end{tabular}

Fonte: Elaboração do autor a partir de bases de dados do IBGE. 


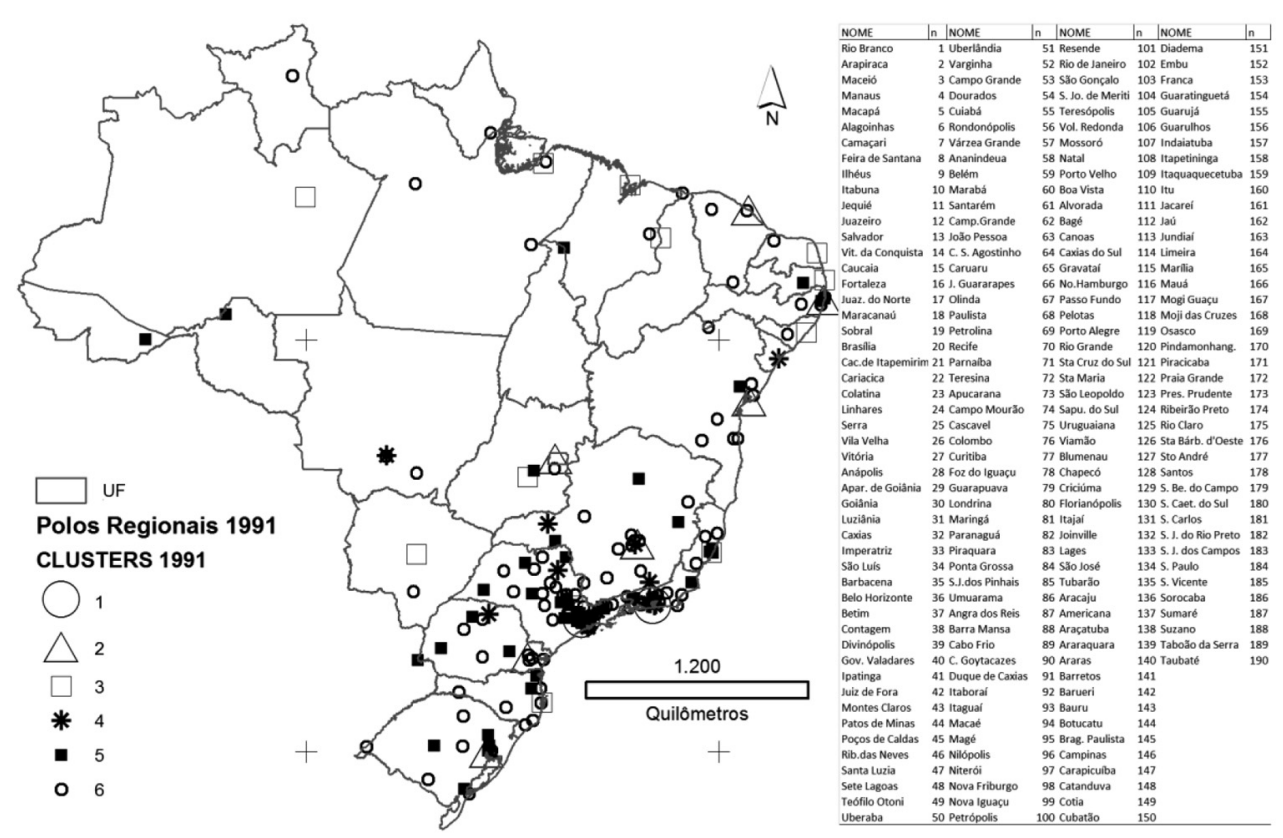

Mapa 3 - Polos regionais 1991

O mapa 4 apresenta o resultado sintético com todos os municípios criados no segundo ciclo de descentralização em relação aos polos regionais mais importantes do país, em 1991. O mapa 4 mostra os novos municípios criados em relação aos polos regionais, classificados hierarquicamente em nível de importância na rede urbana. As regiões de maior destaque em relação ao número de novos municípios criados podem ser mais claramente observadas dessa maneira, destacando-se o noroeste do Rio Grande do Sul, o extremo oeste de Santa Catarina e o sudoeste do Paraná, na região Sul. No Sudeste, o estado de Minas Gerais, em especial as regiões norte e leste de Minas Gerais. No Nordeste, a Paraíba, que novamente se destacaria entre aqueles com maior número de novos municípios criados, repetindo a oportunidade de aumentar as transferências federais para sua área de influência. 


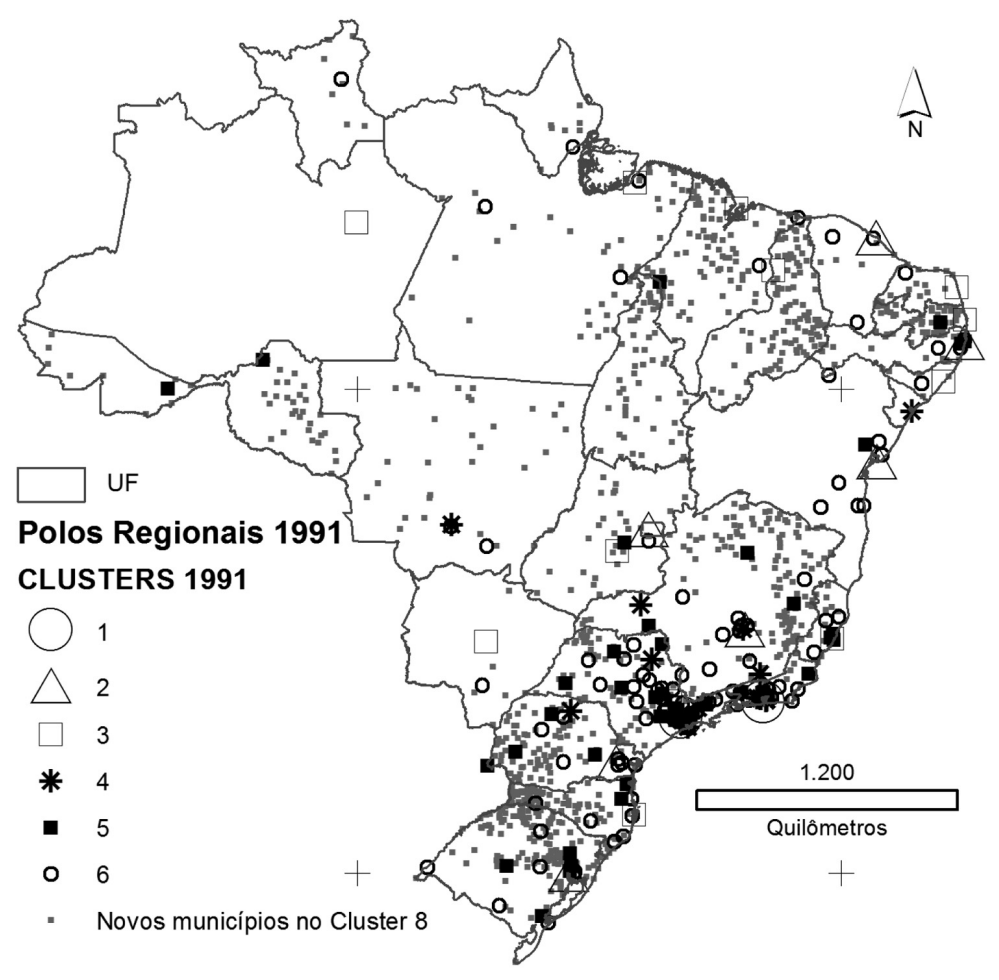

\section{Mapa 4 - Polos Regionais 1991 e novos municípios criados em 1993 e 1997}

Novas áreas seriam praticamente todo o Piauí e grande parte do Maranhão, com destaque para as regiões centrais e o sul do Maranhão.

$\mathrm{O}$ aspecto mais marcante do processo reside no fato de que as semelhanças entre ambos os períodos históricos, as regiões dentro dos estados, não seriam exatamente as mesmas. Mas em relação às grandes regiões geográficas de ocorrência o fenômeno teria uma regularidade, com amplo destaque para a região Sul, desta vez em especial o Rio Grande do Sul, mas também o Nordeste, com grande número de polos que repetiriam sua posição entre os mais beneficiados, como Juazeiro do NorteCE, Campina Grande-PB e Teresina-PI, e novamente Minas Gerais. Estes seriam aos destaques em relação à criação de novos municípios.

Vale identificar aqui o impacto econômico da criação de novos municípios nas áreas de influência dos polos principais beneficiados. A criação de novas unidades não afetaria tanto o repasse dos municípios-mãe, que perderiam as novas unidades por conta dos critérios legais de repasse do FPM, que premiam em termos per capita as menores unidades. Nesse aspecto, mesmo que os municípios-mãe caíssem de classe, passando a receber uma cota menor por conta da perda populacional, cada cota menor significa aumento da cota repassada por habitante. Muitas vezes, também, se esses se mantivessem nas mesmas classes, o valor se manteria na mesma cota. 
Tabela 9 - Polos regionais com maior número de novos municípios instalados em 1993 e 1997 em sua área de influência (20\% maiores)

\begin{tabular}{|c|c|c|c|c|c|c|c|}
\hline Área de influência do polos & anteriores & novos & Total & $\%$ & rank & $\%$ novos & $\begin{array}{l}\text { \% novos } \\
\text { Cumul. }\end{array}$ \\
\hline Chapecó-SC & 127 & 76 & 203 & 37.4 & 1 & $7.04 \%$ & 7.04 \\
\hline Imperatriz-MA & 59 & 55 & 114 & 48.2 & 2 & $5.09 \%$ & 12.13 \\
\hline Juazeiro-BA/Petrolina-PE & 80 & 44 & 124 & 35.5 & 3 & $4.07 \%$ & 16.20 \\
\hline Montes Claros-MG & 58 & 41 & 99 & 41.4 & 4 & $3.80 \%$ & 20.00 \\
\hline Teresina-PI & 63 & 41 & 104 & 39.4 & 5 & $3.80 \%$ & 23.80 \\
\hline São Luís-MA & 57 & 34 & 91 & 37.4 & 6 & $3.15 \%$ & 26.94 \\
\hline Juazeiro do Norte-CE & 147 & 30 & 177 & 16.9 & 7 & $2.78 \%$ & 29.72 \\
\hline Marabá-PA & 40 & 30 & 70 & 42.9 & 8 & $2.78 \%$ & 32.50 \\
\hline Porto Velho-RO & 28 & 29 & 57 & 50.9 & 9 & $2.69 \%$ & 35.19 \\
\hline Campina Grande-PB & 109 & 28 & 137 & 20.4 & 10 & $2.59 \%$ & 37.78 \\
\hline Brasília-DF & 76 & 26 & 102 & 25.5 & 11 & $2.41 \%$ & 40.19 \\
\hline Cascavel-SC & 37 & 25 & 62 & 40.3 & 12 & $2.31 \%$ & 42.50 \\
\hline Passo Fundo-RS & 67 & 24 & 91 & 26.4 & 13 & $2.22 \%$ & 44.72 \\
\hline Ipatinga-MG & 68 & 23 & 91 & 25.3 & 14 & $2.13 \%$ & 46.85 \\
\hline Vitória da Conquista-BA & 80 & 22 & 102 & 21.6 & 15 & $2.04 \%$ & 48.89 \\
\hline Caxias-MA & 51 & 20 & 71 & 28.2 & 16 & $1.85 \%$ & 50.74 \\
\hline Lages-SC & 29 & 20 & 49 & 40.8 & 17 & $1.85 \%$ & 52.59 \\
\hline Araçatuba-SP & 78 & 19 & 97 & 19.6 & 18 & $1.76 \%$ & 54.35 \\
\hline Parnaíba-PI & 19 & 18 & 37 & 48.6 & 19 & $1.67 \%$ & 56.02 \\
\hline Santa Cruz do Sul-RS & 31 & 18 & 49 & 36.7 & 20 & $1.67 \%$ & 57.69 \\
\hline Santa Maria-RS & 54 & 18 & 72 & 25.0 & 21 & $1.67 \%$ & 59.35 \\
\hline Cuiabá-MT & 43 & 16 & 59 & 27.1 & 22 & $1.48 \%$ & 60.83 \\
\hline Teófilo Otoni-MG & 53 & 16 & 69 & 23.2 & 23 & $1.48 \%$ & 62.31 \\
\hline Ananindeua-PA & 38 & 12 & 50 & 24.0 & 24 & $1.11 \%$ & 63.43 \\
\hline Caxias do Sul-RS & 35 & 12 & 47 & 25.5 & 25 & $1.11 \%$ & 64.54 \\
\hline Criciúma-SC & 23 & 12 & 35 & 34.3 & 26 & $1.11 \%$ & 65.65 \\
\hline Guarapuava-PR & 23 & 12 & 35 & 34.3 & 27 & $1.11 \%$ & 66.76 \\
\hline Anápolis-GO & 47 & 11 & 58 & 19.0 & 28 & $1.02 \%$ & 67.78 \\
\hline Governador Valadares-MG & 39 & 10 & 49 & 20.4 & 29 & $0.93 \%$ & 68.70 \\
\hline Jequié-BA & 61 & 10 & 71 & 14.1 & 30 & $0.93 \%$ & 69.63 \\
\hline Mossoró-RN & 93 & 10 & 103 & 9.7 & 31 & $0.93 \%$ & 70.56 \\
\hline Rio Branco-AC & 25 & 10 & 35 & 28.6 & 32 & $0.93 \%$ & 71.48 \\
\hline Umuarama-PR & 44 & 10 & 54 & 18.5 & 33 & $0.93 \%$ & 72.41 \\
\hline
\end{tabular}

Fonte: Elaboração própria a partir de dados do IBGE disponíveis no IPEADATA.

As áreas de influência dos polos regionais de 1991 foram classificadas de acordo com o número de novas unidades que receberam por quintil, sendo que o primeiro quintil tem as AIs dos polos: $20 \%$ maiores números de novas unidades, seguidas pelo segundo quintil, com $20-40 \%$ maiores números de novas unidades, o terceiro quintil daqueles de patamar médio com $40-60 \%$ maiores ou menores. O quarto, com as unidades de $20-40 \%$ menores números de novas unidades, fechando com o quinto, com $20 \%$ menor número de novas unidades.

A tabela 10 mostra que as regiões que mais receberam novas unidades, os quintis superiores, foram aquelas que conseguiram incrementar sua participação no bolo do repasse federal do fundo de participação dos municípios, ao mesmo tempo em que as áreas de influência dos polos que não participaram tão ativamente do processo, os quintis 4 e 5, perderam participação no bolo total do FPM, entre 1994 e 2009. A tabela 10 mostra como o processo de criação de novas unidades em regiões específicas implica em aumento relativo das transferências federais para essas regiões, ao mesmo tempo em que prejudicam as regiões menos beneficiadas. Da mesma maneira, as cidades polo, capazes de fazer a intermediação das trocas e atender com sua oferta de bens e serviços as regiões beneficiadas, provavelmente se beneficiariam do processo de descentralização. Da mesma maneira que o processo aumenta os 
repasses para os estados, as cidades polo que receberam em sua área de influência o maior número de novas unidades também seriam aquelas beneficiadas em relação a outras cidades polo menos beneficiadas por esse processo.

\section{Tabela 10 - Somatório do FPM repassado às áreas de influência dos polos de 1991 em 1994, 2000 e 2009 classificados por quintil em relação ao número de novas unidades criadas}

\begin{tabular}{c|c|c|c|c|c|c}
\hline \multirow{2}{*}{2} & \multicolumn{2}{|c|}{$\begin{array}{c}\text { Somatório do } \\
\text { FPM repassado em 1994 }\end{array}$} & \multicolumn{2}{c|}{$\begin{array}{c}\text { Somatório do } \\
\text { FPM repassado em 2000 }\end{array}$} & \multicolumn{2}{c}{$\begin{array}{c}\text { Somatório do } \\
\text { FPM repassado em 2009 }\end{array}$} \\
\cline { 2 - 7 } & $\mathrm{R} \$$ de 2012 & $\%$ & $\mathrm{R} \$$ de 2012 & $\%$ & $\mathrm{R} \$$ de 2012 & $\%$ \\
\hline 1 & $\mathrm{R} \$ 5,084,329,276$ & 40 & $14,175,715,562$ & 48 & $\mathrm{R} \$ 26,245,351,106$ & 48 \\
2 & $\mathrm{R} \$ 3,275,063,826$ & 26 & $8,800,327,535$ & 30 & $\mathrm{R} \$ 16,663,693,987$ & 30 \\
3 & $\mathrm{R} \$ 1,822,077,710$ & 14 & $4,137,982,927$ & 14 & $\mathrm{R} \$ 6,982,353,065$ & 13 \\
4 & $\mathrm{R} \$ 1,502,868,276$ & 12 & $1,951,127,941$ & 7 & $\mathrm{R} \$ 3,626,241,576$ & 7 \\
5 & $\mathrm{R} \$ 987,820,837$ & 8 & $729,209,765$ & 2 & $\mathrm{R} \$ 1,406,214,395$ & 3 \\
Total & $\mathrm{R} \$ 12,672,159,924$ & & $29,794,363,730$ & & $\mathrm{R} \$ 54,923,854,128$ & \\
\hline
\end{tabular}

Fonte: Elaboração própria a partir de dados do IBGE disponíveis no IPEADATA.

Vê-se que entre os seis maiores AIs em número de novas unidades criadas receberam uma elevada proporção de sua receita total, oriunda dos novos municípios criados. Entre os seis maiores polos que receberam maior número de novas unidades, o montante de FPM destinado aos novos municípios criados atingiria entre 37 e $46 \%$ de todo o repasse de FPM destinado à área de influência do polo. Os valores repassados às novas unidades chegariam também a montantes significativos, entre $\mathrm{R} \$ 700$ e 300 milhões de reais em 2009.

Como a criação de novas unidades municipais privilegiou as pequenas unidades e estas são premiadas com maiores valores de FPM por habitante, as áreas de influência dos polos que mais receberam novas unidades também foram aquelas que mais aumentaram a média recebida de FPM por habitante, como mostra a tabela 11. Se as áreas de influência forem classificadas por quantidade de novas unidades recebidas por quintil, quanto maior o número de novas unidades, maior foi o aumento do repasse médio por habitante para cada uma das regiões. Os dados mostram uma grande distorção nas condições de cada uma das áreas de influência das cidades polo.

Tabela 11 - Média do Repasse do FPM por habitante em 1994, 2000 e 2009 nas áreas de influência dos polos regionais de 1991 classificados por quintil de novos municípios criados ( $R \$$ de 2012)

\begin{tabular}{c|c|c|c|c}
\hline $\begin{array}{c}\text { Quintis de novos } \\
\text { municipios }\end{array}$ & $\begin{array}{c}\text { FPM por habitante } \\
1994\end{array}$ & $\begin{array}{c}\text { FPM por habitante } \\
2000\end{array}$ & $\begin{array}{c}\text { FPM por habitante } \\
2009\end{array}$ & $\begin{array}{c}\text { Variação relative } \\
1994-2009\end{array}$ \\
\hline $20 \%$ maiores & $\mathrm{R} \$ 139.04$ & $\mathrm{R} \$ 326.82$ & $\mathrm{R} \$ 556.59$ & 300 \\
$20-40 \%$ maiores & $\mathrm{R} \$ 110.02$ & $\mathrm{R} \$ 263.14$ & $\mathrm{R} \$ 431.35$ & 292 \\
$40-60 \%$ maiores & $\mathrm{R} \$ 90.32$ & $\mathrm{R} \$ 206.00$ & $\mathrm{R} \$ 300.89$ & 233 \\
$20-40 \%$ menores & $\mathrm{R} \$ 70.79$ & $\mathrm{R} \$ 70.33$ & $\mathrm{R} \$ 113.94$ & 61 \\
$20 \%$ menores & $\mathrm{R} \$ 63.06$ & $\mathrm{R} \$ 42.94$ & $\mathrm{R} \$ 73.05$ & 16 \\
Total & $\mathrm{R} \$ 94.25$ & $\mathrm{R} \$ 180.35$ & $\mathrm{R} \$ 292.62$ & 210 \\
\hline
\end{tabular}

Fonte: Elaboração do autor a partir de bases de dados do IBGE e Secretaria do Tesouro Nacional. 
Os polos regionais brasileiros foram classificados em relação ao número de pequenos novos municípios em sua área de influência em decis. O primeiro decil, por exemplo, agrupa os polos onde o processo tem escala diferenciada em relação aos demais. A figura 4 por exemplo, mostra que os três primeiros decis são significativas diferenças na escala do processo, sendo que o grupo que recebeu o maior número de novas unidades em sua área de influência obteve em média quase 9 mil novos empregos criados na administração pública dos municípios em sua área de influência, mais que o dobro do segundo decil e mais de quatro vezes superior ao terceiro decil.

Como os novos municípios criados são pequenos, com funções urbanas básicas, pode-se esperar que o crescimento do número de novas unidades nos polos regionais resulte em incremento da demanda pelo comércio e serviços dos polos, tendo em vista que essas localidades é que dispõem das funções urbanas da hierarquia superior nessas regiões. Os dados mostram que, de fato, nos decis em que o número de novas unidades atinge uma escala significativa, nos polos do primeiro decil, o crescimento do setor de comércio e serviços foi superior à média geral dos polos e, em especial, ao crescimento naqueles onde não ocorreram emancipações nas áreas de influência. Esses dados indicam que a localização do polo regional numa área com grande concentração de novas unidades pode consistir num diferencial importante para a dinâmica do setor de comércio e serviços dos polos regionais. Um dos aspectos que merecem ser destacados na figura 6 consiste no pico de crescimento do índice de comércio no primeiro decil em 1997, ano em que se tem a consolidação de um grande número dessas novas unidades nessas regiões.
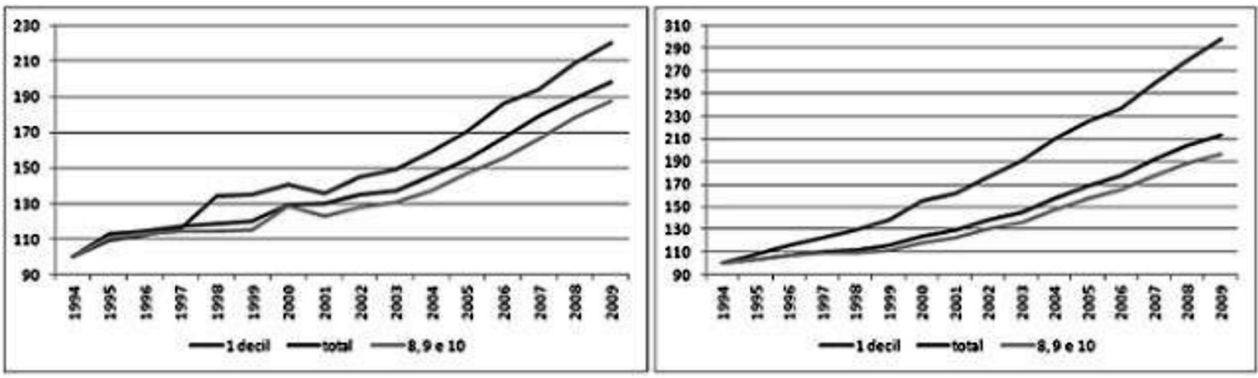

Figura 4 índice de empregos formais nos setores de comércio e serviços dos polos regionais por decis de número de novos municípios criados em sua área de influência 1994-2009

\section{CONSIDERAÇÕES FINAIS}

O trabalho mostrou que existem grande semelhanças entre o processe de criação de municípios nos períodos democráticos, tanto entre 1946-1964 quanto no pós1988. A primeira delas é a intensidade de criação de novos municípios nesses períodos em relação aos ciclos políticos autoritários do Estado Novo e da Ditadura Militar. Além do grande número de novos municípios esses períodos criaram principalmente municípios de pequeno porte populacional. Nesse contexto mostramos que ambos os períodos, o processo de criação de municípios ocorreu em larga escala, com grande concentração espacial em algumas regiões e com predomínio de pequenos municípios. Mostramos que esse processo trouxe implicações econômicas e espaciais porque alterou a distribuição dos repasses federais entre regiões do país. Assim as regiões 
que criaram mais intensamente novos municípios se apropriaram de uma parcela maior dos repasses federais do que as regiões que criaram poucos municípios ou que não criaram. O efeito desse processo é o aumento na renda disponível na área de influência dos polos que receberam maior número de municípios. Como os municípios criados são de pequeno porte populacional e dotados de funções urbanas de hierarquia inferior, o aumento da renda tende a vazar das pequenas localidades para as cidades polo, dotadas das funções urbanas mais complexas. Assim mostramos que as cidades polo das regiões que receberam o maior número de novos municípios apresentaram maior dinamismo das suas atividades de comércio e serviço do que as cidades polo de regiões que não se beneficiaram desse processo.

\section{REFERÊNCIAS}

ABREU, J. F. de; ALVIM, P. R. Determinações de potencialidades a nível espacial para o Estado de Minas Gerais - resultados preliminares. Boletim de Geografia Teorética, Rio Claro, v. 16-17, n. 31-34, p. 294-301, 1986.

BERRY B.J. L.; GARRISON, W. L. A Note on Central Place Theory and the Range of a Good. Economic Geography, v. 34, n. 4 (Oct., 1958), p. 304-311.

CHRISTALleR, W. Central Places in Southern Germany. New Jersey: Prentice Hall, 1966.

CORRÊA, R. L. Rede Urbana e Formação Espacial: uma reflexão sobre o Brasil. Revista Território, Rio de Janeiro, ano 5, n. 8, p. 121-129, 2000.

CORRÊA, R. L. Interações espaciais. In: CASTRO, I. E. de; GOMES, P. C. da C.; CORRÊA, R. L. (Org.). Explorações geográficas. 3 ed. Rio de Janeiro: Bertrand Brasil, 1997.

GOMES, G.M.; MAC DOWEL, M. C. Descentralização política, federalismo fiscal e criação de municípios: o que é mau para o econômico nem sempre é bom para o social. Textos para discussão do IPEA, 706; Brasília: Ipea, fev. 2000.

GRIFFITH, D. A.; AMRHEIN, C. G. Multivariate Statistical Analysis for Geographers. New Jersey: Prentice Hall, 2005.

HAIR, J. F.; ANDERSON, R. E.; TATHAM, R. L.; BLACK, W. C. (2005) Análise Multivariada de Dados. 5a edição. Porto Alegre: Bookman, 2005.

HARTSHORN, T. A. Interpreting the City: An Urban Geography. New York: Wiley, 1980.

HOTTES, R. W. C. Annals of the Association of the American Geographres New York, v. 73, n. 1, p. 51-54.

Instituto Brasileiro de Geografia e Estatística - IBGE Censos Demográficos, 1940, 1950, 1960, 1970, 1980, 1991, 2000 e 2010. Rio de Janeiro: IBGE, 2016. Disponível no www.ibge.gov.br Acesso em Janeiro de 2015.

Ministério do Trabalho e Emprego. Relatório Anual das Informações Sociais 19852010. Brasília: Ministério do Trabelho e Emprego 2015. Disponível em www.mte.gov.br. Acessado em Julho de 2011.

Instituto Brasileiro de Geografia e Estatística - IBGE. Produto Interno Bruto dos Municípios. Série relatórios metodológicos. Rio de Janeiro: IBGE, 2004. 
KING, J. L. Central Place Theory. Beverly Hills:Sage Publications, 1985.

SECRETARIA DO TESOURO NACIONAL - STN Banco de dados de Finanças Públicas dos Municípios Brasileiros. www.stn.fazenda.gov.br, 2013.

SHIKIDA, C. D. A Economia Política da Emancipação de Municípios em Minas Gerais. Brasília: ESAF, 1998. 86 p.

SHIKIDA, C. D. Análise Crítica do Crescimento do Estado Através da Criação de Novos Municípios. Projeto Nemesis - IPEA/RJ. Rio de Janeiro: IPEA, 1999. Disponível em http://www.nemesis.org.br/artigos/a0029.pdf acessado em 04/04/2011.

TOMIO, F. R. de L. Autonomia Municipal e Criação de Governos Locais: A peculiaridade institucional brasileira. Revista da Faculdade de Direito da Universidade Federal do Paraná, Curitiba, v. 42, 2005. Disponível em: <http://ojs.c3sl.ufpr.br/ojs2/ index.php/direito/article/viewFile/5178/3894>

Recebido em julho de 2016

Revisado em janeiro de 2017

Aceito em janeiro de 2017 